\title{
Disidencias y prevenciones destacadas de la Corte Suprema en torno a las desvinculaciones del personal a contrata, periodo 2016- 2020: una mirada hacia el devenir de la jurisprudencia
}

\section{Outstanding dissents and forethought of the Supreme Court related to the dismissal of public employees, period 2016 to 2020: a perspective on the development of the jurisprudence}

Juan Ignacio Paillán Aguilar*

The prophetic dissents are still there, though we are not in a position until sometime later fully to appreciate which dissents fall into this category ${ }^{1-2}$.

William Fletcher

Este trabajo tiene por objeto analizar las principales disidencias y prevenciones de la Corte Suprema entre los años 2016 a 2020, relativas a las desvinculaciones del personal a contrata, reconociendo que éstas podrían transformarse en la opinión que prevalezca en el futuro, pues tienen fundamento
This paper intends to analyze the main dissents and forethoughts of the Supreme Court from 2016-2020, related to the dissmisal of public employees. This recognizing that these could become the prevailing opinion in the future as they have enough foundation to be considered

\footnotetext{
* Abogado, Magister en Derecho Regulatorio LLM Pontificia Universidad Católica de Chile. Correo electrónico: jipaillan@uc.cl. Dirección postal: Liquidámbar tres 448, Maipú, Santiago de Chile.

1 FletCher 2009, 295.

2 "Los disensos proféticos todavía están ahí, aunque no estamos en condiciones hasta algún tiempo después de apreciar plenamente qué disensiones entran en esta categoría" Artículo recibido el 24 de enero de 2021 y aceptado el 20 de mayo de 2021.
} 
suficiente para ser consideradas como la vía idónea para crear nueva jurisprudencia. Asimismo, se analizan disensos y prevenciones que carecen de un supuesto factico que permita incluirlas en el grupo anterior, pero que, sin embargo, favorecen y aportan a la discusión, obligando a que los jueces de mayoría desarrollen de manera más acabada sus fundamentos.

Palabras clave: Disidencias, prevenciones, empleo público, jurisprudencia, Corte Suprema. as the cornerstones to create new jurisprudence. Furthermore, we are going to be analyzing dissents and forethoughts that do not contain factual assumptions which would allow them to be included in the previous group. However, they would benefit and contribute to the discussion, forcing judges to develop more complete argumentation.

Keywords: Dissents, forethought, public employee, jurisprudence, Supreme Court.

\section{Introducción}

En el año 2016, la Contraloría General de la República, mediante el Dictamen $N^{\circ} 85.700$-complementado posteriormente a través del Dictamen $N^{\circ} 6.400$, de 2018-, estimó necesario impartir nuevas instrucciones a los servicios públicos con el objeto de establecer criterios claros respecto a las renovaciones y términos anticipados del personal a contrata, imponiendo de esta manera, vía jurisprudencia administrativa, la institución de la confianza legítima.

A grandes rasgos, la jurisprudencia del ente de control respecto a la confianza legítima, se traduce en que no resulta procedente que la administración pueda cambiar su práctica, ya sea con efectos retroactivos o de forma sorpresiva, cuando una actuación continuada haya generado en la persona la convicción de que se le tratará en lo sucesivo y bajo circunstancias similares, de igual manera que lo ha sido anteriormente ${ }^{3}$, así, dicha confianza, se genera en el caso de que un funcionario se le haya renovado, con anterioridad, dos o más veces su contrato. Lo anterior, no es óbice para que la administración pueda ponerle término a una contrata, es decir, no se configura con la jurisprudencia de la Contraloría una prohibición para la administración en esta materia, sino que un deber de motivación en caso de no renovación o poner término anticipado, mandatando el organismo fiscalizador que dichas decisiones deberán contener "el razonamiento y la expresión de los hechos y fundamentos de derecho en que se sustenta"; por lo que no resulta suficiente para fundamentar esas determinaciones la expresión "por no ser necesarios sus servicios" $u$ otras análogas 4 .

En este contexto, nuestra Corte Suprema, conociendo en segunda instancia de los recursos de protección interpuestos en contra de las decisiones de los servicios que han puesto término a contratas, ha emanado una rica jurisprudencia en la materia, teniendo como uno de sus principales funda-

\footnotetext{
${ }^{3}$ Dictamen $\mathrm{N}^{\circ} 22.766$ (2016).

4 Dictamen Nº.400 (2018).
} 
mentos la jurisprudencia administrativa relativa a la confianza legítima de la Contraloría General de la República.

De esta forma, desde el año 2016 y mayormente desde el 2018, nuestro máximo tribunal ha ido estableciendo una fuerte jurisprudencia con miras a proteger el empleo público, adoptando el criterio de la confianza legítima e incluso, en algunos casos, yendo más allá de lo dispuesto por Contraloría. De esta forma, alguna jurisprudencia reciente, ha dispuesto que los funcionarios a contrata solo pueden ser cesados en sus funciones por sumario administrativo derivado de una falta que motive su destitución o por una calificación anual que así lo permita ${ }^{5}$, aumentando el estándar establecido por la Contralaría en cuanto protección al empleo se trata.

De los criterios anteriores se ocupó de forma minuciosa Alejandro Vergara, en un número especial de esta Revista ${ }^{6}$, en la que se sintetiza y grafica el resultado de una investigación de un caudal de casi 900 sentencias de la Corte Suprema de una década en veinte temas relevantes de la praxis del derecho administrativo. Su formato es sintético. Respecto de cada tema se señala: los hechos que dan origen a la conectividad; la ratio iuris decidendi; gráficos en que queda en evidencia la conducta lineal o zigzagueante tanto de la Sala como de sus ministros y abogados integrantes; un análisis de tal comportamiento; $y$, un recuento exhaustivo de sentencias. El resultado: constantes vacilaciones de la Corte Suprema; una baja cantidad de temas en que existe líneas de jurisprudencia uniforme; y, una conducta errática de algunos de sus ministros y abogados integrantes ${ }^{7}$.

Ahora bien, lo que interesa a este estudio, son las disidencias y prevenciones de la materia en análisis, específicamente desde el 2016 a la fecha, puesto que han surgido importantes criterios que en el futuro puede que se transformen en mayoría, transformándose así, dichas disidencias y/o prevenciones, eventualmente, en proféticas.

\section{Prevenciones y disidencias}

\section{Aspectos Generales}

La doctrina ha admitido que las disidencias contribuyen a legitimar el rol de la Corte; evitan el problema de accountability que se crea a través de la regla de secreto; son útiles para colaborar con futuros (y normalmente positivos) cambios en el ordenamiento jurídico; fortalecen la calidad del razonamiento del voto de mayoría; y tiene un saludable efecto que modera la posición de la mayoría, aunque sin alterarla en el resultado ${ }^{8}$.

\footnotetext{
5 Véase roles Corte Suprema No 38.888-2019 y N 18.881-2020.

6 Revista de Derecho Administrativo Económico № 28, número especial, marzo de 2019.

7 Vergara 2019, 5.

8 Verdugo 2011, 251.
} 
En efecto, la disidencias y prevenciones respecto a las desvinculaciones de las contratas han contribuido en nuestra jurisprudencia para cambiar los criterios de mayoría y adoptar los razonamientos que en un pasado fueron minoría. Esto tiene una especial relevancia en la materia, puesto que los cambios en el derecho no son frecuentes, y en caso de darse, conllevan un paulatino cambio que generalmente demora una cantidad considerable de tiempo, situación que no se advierte en el caso del empleo público -especialmente con las contratas-, puesto que desde el año 2016 la Corte Suprema ha innovado en sus criterios y las que en algún tiempo fueron minorías se han transformado rápidamente en la posición de la mayoría en la tercera sala de nuestro Máximo Tribunal.

En la práctica, el juez que ha promovido más cambios desde prevenciones y disidencias en la jurisprudencia de la tercera sala de nuestra Corte Suprema, ha sido el ministro Sergio Muñoz, quien, verbigracia, ya desde el año $2017^{9}$ postulaba que la fórmula usualmente utilizada por los servicios públicos para desvincular a los funcionarios a contrata, esto es "mientras sean necesarios sus servicios", se relaciona con un hecho objetivo, por lo que se debe prescindir de elementos subjetivos que digan relación con la persona que sirva en el cargo, puesto que en este último caso, se configuraría una desviación de poder. Dicha disidencia pasó a transformarse en mayoría asentada en la tercera sala desde el año $2018^{10}$.

En cuanto a prevenciones, que más tarde se transformaría en el voto de la mayoría, es destacable aquella del Ministro Muñoz en la cual indicó que:

[...] un cargo a contrata que ha tenido más de dos períodos de renovación, por lo cual se extiende por más de dos años ininterrumpidamente, solamente se puede terminar su relación estatutaria por sumario administrativo derivado de una falta que motive su destitución o por una calificación anual que así lo permita ${ }^{11}$.

Razonamiento que a la postre se transformaría en el criterio dominante de la Corte Suprema ${ }^{12}$.

Como se puede apreciar, el efecto de las disidencias y prevenciones en la materia ha tenido un fuerte impacto en la jurisprudencia, lo cual trae como consecuencia que deba mirarse con especial importancia éstas, debido a que pueden ser un vital antecedente para aproximar la jurisprudencia que puede devenir en el futuro. Este razonamiento es ampliamente acogido por autores como William Fletcher ${ }^{13}$, quien ha indicado que en relación a las disidencias judiciales, los jueces pueden transformarse en profetas, señalando el camino

\footnotetext{
9 Corte Suprema Rol No 34.532-2017.

10 Véase roles Corte Suprema No 16.455-2018, N 16.854-2018, № 16.858-2018.

11 Rol Corte Suprema No 16.866-2018.

12 Véase Corte Suprema Rol Nº 38.888-2019 y N 18.881-2020.

13 Fletcher 2009, 295.
} 
hacia el futuro, mostrándonos en lo que debemos convertirnos ${ }^{14}$, en el mismo sentido se manifestado Joe Mclntyre ${ }^{15}$, quien refiere que una disidencia puede 'debilitar' la posición de la mayoría, pero también puede fortalecer la ley al enriquecer el 'mercado legal de ideas', manteniendo 'vivas las opciones para el futuro' y actuando como un 'faro' para desarrollos futuros ${ }^{16}$.

En atención a lo expuesto, el presente estudio se propone como objeto, recopilar las más destacadas prevenciones y disidencias de la tercera sala de la Corte Suprema, sobre desvinculaciones de funcionarios a contrata, durante el periodo comprendido entre los años 2016-2020, para así, realizar una prognosis jurisprudencial que permita vislumbrar la senda que seguirá la tercera sala en la materia.

2. Las prevenciones y disidencias en la tercera sala de la Corte Suprema en torno a la desvinculación de contratas

a) Solo se les puede otorgar protección a los funcionarios a contrata que ingresaron a la Administración del Estado a través concurso público

Señala el abogado integrante Pierry, a través de disidencias ${ }^{17}$ y prevencio- $^{-}$ nes ${ }^{18}$, que solo los funcionarios a contrata que ingresaron mediante concurso público a la Administración del Estado son dignos de otorgárseles protección, v. gr. la confianza legítima. Para construir su tesis, Pierry tiene como punto de partida el artículo 38 del texto constitucional, el cual señala, en lo que interesa, que "Una ley orgánica constitucional determinará la organización básica de la Administración Pública, garantizará la carrera funcionaria y los principios de carácter técnico y profesional en que deba fundarse, y asegurará tanto la igualdad de oportunidades de ingreso a ella [...]". De esta forma, indica que la única forma en que tan precisa y categórica disposición pueda cumplirse es mediante el ingreso a la Administración del Estado a través de un concurso público.

En este sentido, añade que, de acuerdo a la Constitución, son los cargos de planta aquellos que deben ser provistos mediante concurso público, mientras que los cargos a contrata lo son por plazo definido, así al no ser

\footnotetext{
14 Señala Fletcher que: "In these cases, the Justices have been our secular prophets, interpreting the central text of our civic faith, the United States Constitution. These Justices have pointed the way to our future, showing us what we and our government can and should become. This is a justly celebrated function -indeed, perhaps the most important function- of dissent in our judicial system. But the function of dissent has changed over the years. The prophetic dissents are still there, though we are not in a position until sometime later fully to appreciate which dissents fall into this category".

15 McintYre 2016, 445.

16 Señala Mclntyre que: "A dissent may 'weaken' the majority position, but may also strengthen the law by enriching the legal 'marketplace of ideas', keeping 'alive choices for the future' and acting as a 'beacon' for future developments".

17 Véase Corte Suprema roles No 16.779-18 y 29.477-18.

18 Véase Corte Suprema roles No 16.887-18 y 15.478-19.
} 
éstos de planta, no son provistos por concursos, por lo que no gozan de inamovilidad.

Sin embargo, Pierry reconoce que la realidad ha superado a la ley, puesto que los cargos a contrata -los cuales deberían ser la excepción frente a los cargos de plantas-, han pasado a transformarse en la regla general, superando en algunos casos a la planta, razón por la que precisamente la Contraloría General de la República ha intervenido e innovado en su jurisprudencia mediante la confianza legítima. Consecuencialmente, señala que no obstante la intervención de Contraloría mediante su jurisprudencia de la confianza legítima "[...] el problema constitucional permanece, ya que si se otorga inamovilidad al funcionario a contrata, nombrado sin concurso público y en forma discrecional por la autoridad, se está violando en forma flagrante el texto constitucional" 19 .

De esta forma, concluye que

"[...] el funcionario a contrata ha accedido a su cargo mediante concurso público, se abre la posibilidad para que pueda otorgársele protección, pues su ingreso no ha sido producto de una decisión discrecional de la autoridad, que no otorga igualdad de oportunidades a todos los ciudadanos que cumplen con los requisitos, sino que por medio de un concurso, que sí cumple con la disposición de la Constitución Política"20.

Ahora bien, el razonamiento propuesto por Pierry, tiene bastante sentido a la luz de lo dispuesto en el precitado artículo 38 de la Carta Magna, puesto que:

1. El mencionado artículo dispone "Una ley orgánica constitucional determinará la organización básica de la Administración Pública, garantizará la carrera funcionaria y los principios de carácter técnico y profesional en que deba fundarse, y asegurará tanto la igualdad de oportunidades de ingreso a ella"21, de esta forma si el actual voto de mayoría en la tercera sala de la Corte Suprema señala que la relación estatutaria del personal a contrata que cuenta con confianza legitima solo puede terminar por sumario administrativo, derivado de una falta que motive su destitución o por una calificación anual que así lo permita 22 , lo que se está asumiendo de forma tácita, es que estos son parte de una verdadera carrera funcionaria al homologar las causales de término de empleo a las mismas que el personal de planta. En este contexto, no se aprecia razón para no hacer lugar al razonamiento del abogado integrante Pierry, toda vez que, de asumir una posición contraria, se estaría dotando de mayores beneficios al personal a contrata al ser su designación a criterio discrecional de la autoridad.

\footnotetext{
19 Véase sentencias Corte Suprema roles No $16.887-18,15.478-19,16.779-18$ y 29.477-18.

20 Ibídem.

21 Artículo 38 de la Constitución Política de la República.

22 V. gr. sentencia Corte Suprema rol N 15.478-2019.
} 
2. Por otra parte, el argumento anterior puede complementarse por lo señalado por el abogado integrante Pallavicini en sus disidencias contenidas en las sentencias roles $N^{\circ} 7.295-19,8.396-19,26.194-19$, 14.915-20, 76.532-29, entre otras, todas de la Excma. Corte Suprema, en las cuales indica que los funcionarios a contrata ingresan a un servicio público sin cumplir con las ritualidades de ingreso a que están sujetos los funcionarios de planta, quienes, por lo demás, se incorporan en el último grado del escalafón al cual son asimilados, en tanto que los funcionarios a contrata lo hacen en el grado que disponga la autoridad administrativa y que de ordinario es muy superior al grado más bajo del escalafón respectivo.

3. En este contexto normativo, se estaría transgrediendo la garantía constitucional de la igualdad ante la ley, contenida en el artículo $19 \mathrm{~N}^{\circ} 2$ de la norma fundamental, puesto que, en situaciones de igual naturaleza, se le estaría imponiendo al personal de planta ingresar a la administración del Estado por concurso público, mientras que el personal a contrata, con las mismas prerrogativas del personal de planta, ingresa mediante la decisión discrecional de la autoridad.

Claro está, que el criterio propuesto por Pierry pugna con toda la jurisprudencia judicial y administrativa predominante en la actualidad, la cual apunta a proteger al personal a contrata, cualquiera sea su modalidad de ingreso y mientras cuente con confianza legítima ${ }^{23}$, y con razón, puesto que puede señalarse sin tapujos que actualmente el ingreso del personal a contrata a la Administración del Estado es excepcionalmente a través de concurso público. En este sentido, el punto de vista expuesto si bien tiene concordancia con lo dispuesto en nuestro ordenamiento jurídico, difícilmente se concilia con la realidad en torno al empleo público en nuestro país. De cualquier modo, se hace notar un punto importante en cuanto a la materia en análisis, de esta suerte si en un futuro la realidad se concilia con el argumento en estudio, no se vislumbran dificultades para que éste se convierta en la posición mayoritaria de nuestro Máximo Tribunal.

b) La fórmula "mientras sean necesarios sus servicios" en los términos anticipados de las contratas: la tesis objetiva y subjetiva

La fórmula "mientras sean necesarios sus servicios", usualmente utilizada en los actos administrativos del personal a contrata para sus vinculaciones con la administración, ha sido objeto de dos interpretaciones por la jurisprudencia de la tercera sala, al disponerse el término anticipado a éstas.

Por un lado tenemos la tesis objetiva, la cual comenzó de forma tímida con disidencias por parte del ministro Sergio Muñoz $^{24}$ y que actualmente se

\footnotetext{
${ }^{23}$ Esta ha sido la regla general, pero existen excepciones, como lo son cargos de confianza exclusiva.

24 Véase sentencias Corte Suprema roles No 34.532-17, 39.403-17, 1399-18 y 2210-18, entre otras.
} 
ha transformado en la tesis predominante $25-26$. Este raciocino postula que dicha fórmula, al utilizarse para desvincular a un funcionario, se relaciona con un hecho objetivo, esto es que los servicios prestados no son necesarios, debiendo prescindirse de elementos subjetivos que digan relación con la persona que sirve el cargo, de este modo en caso de que el servicio esgrima como argumento que un funcionario tiene bajo desempeño o se ha ausentado por un prolongado tiempo por razones de salud, se estaría apuntando a razones de carácter subjetivo que nada tienen que ver con la necesidad de los servicios del funcionario, lo que se vincula con el cargo y no con las circunstancias personales de quien lo sirve.

De esta forma, al verificarse argumentos como los recién enunciados para poner fin a una contrata mediante la fórmula en estudio, se tiene como consecuencia que el acto no estaría motivado, puesto que al ostentar el enunciado un carácter objetivo, mal podrían argüirse razones subjetivas. Así pues, en las condiciones apuntadas, la motivación expresada en el acto que pone término a una contrata no guardaría ninguna relación con el motivo esgrimido por la autoridad, cual es la necesidad de los servicios, configurándose de esta forma, una desviación de poder ${ }^{27}$ con respecto al elemento fin del acto, lo que constituye un vicio que lo torna susceptible de anulación.

Por otra parte, tenemos la minoría disidente, adherentes de la tesis subjetiva, la cual es la que interesa a nuestro estudio. Dicha tesis postula que la fórmula en análisis no alude a que tal vinculación se mantendría mientras sean necesarios "sus cargos", sino que más bien mientras fueren necesarios sus servicios, entendidos éstos en relación a las especiales habilidades del funcionario a contrata para desarrollar la función encomendada -carácter subjetivo-, sin perjuicio de los requisitos propios del cargo, por lo que al ponerse término anticipado a una contrata "por no ser necesarios sus servicios", no se incurriría en acto ilegal ni arbitrario alguno por parte de la autoridad administrativa, la que actuaría con estricto apego a la normas legales que regulan la materia ${ }^{28}$.

Admitir la tesis subjetiva implica otorgar una amplia discrecionalidad a la autoridad, ya que al entregársele la ponderación de cuáles son las habilidades del funcionario a contrata para desarrollar la función encomendada, puede dar paso, por ejemplo -como ya se ha visto- a que con los cambios de ciclos políticos en el gobierno, la autoridad esgrima razones falaces para

\footnotetext{
25 Véase sentencias Corte Suprema roles $N^{\circ} 16.510-18,16.455-18,16.854-18,16.858-18$ y 71.955-20 entre otras.

26 Sin perjuicio de lo señalado, ya en el año 2016, en la causa Corte Suprema rol N ${ }^{\circ}$ 78.937-16, esta Corte acogió dicha tesis, la que, en aquella ocasión, fue una excepción en vista de la integración de la sala y no fue hasta el año 2018 en que la tesis objetiva se consolidó.

27 La actual jurisprudencia de la E. Corte Suprema estima que cinco los elementos del acto administrativo, a saber, la competencia, la forma, el fin, los motivos y el objeto.

28 Esta es la argumentación que se recoge en la disidencia de la ministra señora Egnem y del Abogado Integrante señor Quintanilla, en la sentencia de la causa Corte Suprema rol N 78.937-2016.
} 
acomodar al personal de su corriente política ${ }^{29}$, poniendo en riesgo la continuidad y protección del empleo que tanto ha cautelado la jurisprudencia administrativa y judicial, constituyéndose en estos casos, -tal como lo indica García de Enterría citando a Hans Huber- el poder discrecional como un verdadero caballo de Troya en el seno del Derecho Administrativo de un Estado de Derecho ${ }^{30}$.

Asimismo, acoger el subjetivismo en la fórmula en estudio, resulta extremadamente difícil de controlar por la vía administrativa o judicial, puesto que el hecho determinante que configura el término anticipado-especiales habilidades del funcionario que habilitan la necesidad de sus servicios- queda al arbitrio de la autoridad. En este orden de ideas, esgrimir que un funcionario no tiene las habilidades que se requieren, resulta ser el elemento reglado para ejercer la facultad discrecional ${ }^{31}$, lo cual, por si solo, es bastante feble, ya que la valorización política de la realidad podrá acaso ser objeto de una facultad discrecional, pero la realidad como tal, si se ha producido el hecho o no se ha producido y cómo se ha producido, esto ya no puede ser objeto de una facultad discrecional, porque no puede quedar al arbitrio de la administración discernir si un hecho se ha cumplido o no se ha cumplido, o determinar que algo ha ocurrido si realmente no ha sido así. El milagro, podemos decir, no tiene cabida en el campo del Derecho Administrativo ${ }^{32}$.

La subjetiva disidencia expuesta, difícilmente logrará asentarse como la doctrina mayoritaria de la Corte, sin embargo, es de especial interés que esta tesis haya sido acogida excepcionalmente ${ }^{33}$ en vista de la integración de la sala de aquel entonces, lo cual hace notar la relevancia de los abogados integrantes en la jurisprudencia suprema ${ }^{34}$.

29 Tal como lo alegó el recurrente en la sentencia causa Corte Suprema rol N²0.863-18.

30 García de Enterría 1983, 24.

31 Señala García de Enterría, en su "Lucha contra las inmunidades del poder" (1983, 25), que "[...] en todo acto discrecional hay elementos reglados suficientes como para no justificarse de ninguna manera una abdicación total del control sobre los mismos".

32 García de Enterría 1983, 31 y ss.

33 Véase sentencia Corte Suprema Rol N²4.943-2018 considerando quinto: "Que, como se observa, la autoridad administrativa denunciada se encontraba legalmente facultada para cesar los servicios a contrata de la parte recurrente, servicios cuya principal característica es la precariedad en su duración, supeditada a las necesidades de la entidad empleadora, de manera que al acudir la recurrida precisamente a esta causal solo ha hecho uso de la facultad antes descrita.

En este contexto, se debe precisar que la autoridad fundó su decisión refiriendo que, si bien las competencias de la actora son apropiadas, lo cierto es que no se logró el resultado deseado, detectándose la necesidad de que quien ejerza el cargo cuente con competencias en materias contables. Tales razones no solo son válidas, sino que, además, al contrario de lo referido en la sentencia en alzada, aquellas no son inconciliables, puesto que, se establece claramente que, si bien la actora tuvo un buen desempeño, las exigencias actuales determinan una mayor competencia en materia contable, razón que determina la necesidad de poner término a la contrata, ejerciendo así, fundadamente, la facultad que le fue entregada por el legislador".

34 En la sentencia causa Corte Suprema Rol N²4.943-2018, en que fue acogida la tesis subjetiva, la tercera sala estaba integrada por los Ministros Sra. María Eugenia Sandoval G. y Sra. Ángela Vivanco M., el Ministro Suplente Sr. Rodrigo Biel M. y los Abogados Integrantes Sr. Julio Pallavicini M. y Sra. María Cristina Gajardo H. 

configurar la confianza legítima

Este postulado corresponde a una prevención de los ministros Sergio Muñoz y Juan Eduardo Fuentes ${ }^{35}$, quienes indican que si un funcionario a contrata, previamente ha prestado servicios a honorarios para el mismo servicio, realizando funciones siempre vinculadas al mismo cargo de forma continua, sumando un total de dos o más periodos, le asiste la confianza legítima de que su vínculo se renovará por los próximos períodos.

Así las cosas, para que proceda esta tesis, deben concurrir los siguientes requisitos copulativos:

1. Que una persona sirva actualmente como funcionario a contrata.

2. Dicho funcionario, previo a su contratación, debe haber prestado servicios en la modalidad de honorarios.

3. Las funciones realizadas como honorario y funcionario a contrata deben ser siempre vinculadas al mismo cargo.

4. Debe existir continuidad entre los servicios prestados a honorario y funcionario a contrata.

5. La continuidad de los servicios debe darse en el mismo órgano de la Administración del Estado.

6. El tiempo servido a honorarios y como funcionario a contrata debe totalizar dos o más periodos (dos años o más).

Este criterio, sin duda avanza aún más en la protección del empleo público, no obstante, se encuentra en una vereda opuesta a lo que ha dictaminado la Contraloría General de la República ${ }^{36}$ en la materia. Con todo, es alentador que existan este tipo disidencias, teniendo presente la precarización del empleo público, sobre todo para los servidores a honorarios, en que la Contraloría ha admitido que quienes laboran para la Administración bajo la mencionada modalidad, no son funcionarios y la principal norma reguladora de sus relaciones con ella es el propio contrato, careciendo de los derechos que el ordenamiento jurídico contempla para aquellos, de modo que solo poseen las prerrogativas estipuladas en dicho pacto, sin perjuicio que en este puedan reconocérseles derechos similares a los que las leyes disponen para los servidores del Estado, no así superiores ${ }^{37}$, viéndose obligados estos ser-

\footnotetext{
35 Prevención de la sentencia Corte Suprema Rol N³1.312-2018.

36 Señala el Ente Contralor, mediante su Dictamen $N^{\circ} 6.400$, de 2018, que actualiza instrucciones y criterios complementarios fijados en el Dictamen $N^{\circ} 85.700$, de 2016, sobre confianza legítima en las contratas que: "[...]se debe anotar que el señalado dictamen arriba a las conclusiones reseñadas en el apartado I de estas instrucciones en relación con sucesivas designaciones a contrata, por lo que aquellas solo aplican para ese tipo de vinculaciones -o contrataciones similares, aun cuando no tengan la misma denominación-y no para los contratos a honorarios" (énfasis añadido).

37 Dictamen N²9.461 (2017).
} 
vidores a recurrir a la judicatura laboral, la cual ha ido reconocido que existe un vínculo de subordinación y dependencia, y por consiguiente una relación laboral entre el servidor a honorarios y el servicio ${ }^{38}$.

Asimismo, esta disidencia tiene mucho sentido a la luz de lo dispuesto en el artículo 18 de la Ley $N^{\circ} 20.948$, el cual prescribe que:

[...] Durante el año en que se produzcan vacantes de empleos a contrata afectos a la dotación máxima de personal fijada en la Ley de Presupuestos del Sector Público, por la dejación voluntaria de los cargos que realicen los funcionarios a contrata que se acojan a esta ley, dichas vacantes solo podrán reponerse modificando la calidad jurídica del personal de honorario a contrata, reduciéndose por el solo ministerio de la ley el número de honorarios fijados en las glosas presupuestarias del respectivo servicio, en igual cantidad ${ }^{39}$.

De esta forma, se ha reconocido mediante la precitada ley, que los servidores a honorarios, cumplidos ciertos requisitos, pueden cambiar la modalidad de su contratación, lo cual tiene plena concordancia con otorgar confianza legítima en los términos que se estudia.

d) Es improcedente el recurso de protección cuando se ha optado primero por la impugnación administrativa ante la Contraloría General de la República

Esta disidencia es planteada por la ministra Sandoval ${ }^{40}$, en la cual señala que si un funcionario contratado, es desvinculado y luego reclama de dicho acto de conformidad al artículo 160 de la Ley $N^{\circ} 18.834$ o del artículo 156 de la Ley $N^{\circ} 18.883$, según sea el caso, se entiende que acepta de manera implícita la decisión del órgano de control.

A mayor abundamiento, se señala en dicha disidencia que al optar por la vía administrativa, se entiende que se acepta de manera tácita la decisión del órgano de control, arguyendo que de otra forma, se habría interpuesto inmediatamente la acción constitucional de protección y, además, porque la Contraloría no solo efectúa un control de legalidad del acto administrativo, sino que también revisa su conformidad con los preceptos y principios de la Carta Fundamental y con su propia jurisprudencia administrativa.

De esta forma, concluye que la única forma en que la acción constitucional pueda prosperar, es si se acredita que el ente de control incurrió en un acto ilegal y arbitrario que sea ostensiblemente contrario a la Constitución, leyes o su propia jurisprudencia, pero en ningún caso si se trata acerca de la interpretación del derecho, puesto que, de tal forma se desnaturaliza la acción constitucional, erigiéndose la Corte Suprema como un Tribunal Revisor

\footnotetext{
38 Véase, v. gr., sentencias Rol N42.636-2017 N4.591-2018 y N 15.615-19, entre otras de la E. Corte Suprema.

39 Ley $N^{\circ} 20.948$, de 2016.

40 Disidencias en las sentencias Corte Suprema rol N²9.869-2019, N³8.888-2019 y $N^{\circ} 71.955-2020$.
} 
de última instancia respecto de las decisiones de la Contraloría General de la República ${ }^{41}$.

Pues bien, la disidencia en análisis, entra en directa pugna con toda la jurisprudencia que ya ha emanado la Corte Suprema con anterioridad, puesto que dicha magistratura, no en pocas ocasiones ha realizado interpretaciones que se alejan de lo expuesto por la Contraloría. De esta forma, según este criterio, bastaría con el control de legalidad que ejerce la Contraloría, el que, una vez realizado, sería la decisión que implícitamente aceptaría el reclamante, por lo que el derecho a recurrir jurisdiccionalmente a través de la acción de protección sería inviable.

En este sentido, el razonamiento expuesto parece omitir lo dispuesto en el artículo 54 de la Ley $N^{\circ} 19.880$, la cual tiene carácter supletorio respecto a procedimientos administrativos especiales, como lo sería la reclamación establecida en los artículos 156 y 160 de las leyes citadas ut supra. El citado artículo 54 dispone la regla general en esta materia, otorgando a los particulares un derecho de opción para utilizar a su arbitrio los procedimientos o los procesos administrativos de impugnación, según estimen conveniente. En otras palabras, el ordenamiento jurídico nacional no exige un orden de prelación entre los procedimientos y procesos administrativos de impugnación, ni aún el paso previo por los primeros para llegar a los segundos, sino que otorga a los administrados el derecho de elegir la vía de impugnación específica en cada caso $^{42}$.

Como se puede observar, el diseño legislativo reconoce a los particulares un derecho de opción en esta materia, que le permite un agotamiento de la vía administrativa antes de llevar el asunto ante los tribunales de justicia, pero sin llegar a configurar un impedimento a los particulares para el acceso directo a aquellos ${ }^{43}$.

Finalmente, es del caso mencionar que esta posición jurisprudencial difícilmente prevalecerá en la tercera sala, no solo por los argumentos ya expuestos, sino que también en vista de que vulnera un principio general del derecho público chileno, cual es el de la "impugnabilidad" de todo acto administrativo, de cualquier órgano que ejerza actividad administrativa, cualquiera sea su naturaleza o jerarquía, tal como lo reconoce el artículo $10^{\circ}$ de la Ley N 18.575, Orgánica Constitucional de Bases Generales de la Administración del Estado, como asimismo violaría de modo ostensible un derecho fundamental como es el derecho a la acción, al acceso a la justicia, a la tutela judicial efectiva y al juez natural que le reconoce y asegura la Constitución a toda persona (artículo $\left.19 \mathrm{~N}^{\circ} 3\right)^{44}$.

\footnotetext{
${ }_{41}$ Disidencia sentencia Corte Suprema rol N²9.869-19.

42 Ferrada 2011, 255.

43 lbíd.

44 Soto Kloss 2012, 466.
} 


\section{e) La confianza legítima no existe}

El título de este apartado resume, en lo medular, la disidencia planteada por el abogado integrante Pallavecini en distintas sentencias de nuestra Corte Suprema ${ }^{45}$ : la confianza legítima no existe. Como primer acercamiento debemos indicar que dicha idea no tiene absolutamente ninguna cabida en nuestro sistema, en donde la doctrina y la jurisprudencia judicial y administrativa han admitido que la confianza legítima es una institución que llegó para quedarse.

Sin embargo, los argumentos del abogado integrante Pallavecini son interesantes, parte señalando que, contrario a todo lo que ha expuesto la Máxima Magistratura en su jurisprudencia actual, al ser los empleos a contrata de carácter transitorio, esto es, que durarán, como máximo, hasta el 31 de diciembre de cada año, cumplida dicha fecha, expirarán en sus funciones por el solo ministerio de la ley, indicando además, que históricamente, la jurisprudencia de la Contraloría General de la República ha entendido que ella opera de pleno derecho y no requiere de resolución alguna de la autoridad (véanse dictámenes $N^{o s}$ 6.622, de 1965; 54.085, de 1969; y 19.020, de 1990, y 4.450, de 2019, entre otros).

En este panorama, la autoridad facultada para hacer el nombramiento no le asiste ninguna obligación jurídica de renovar las funciones del empleado a contrata en la fecha recién indicada o de justificar por qué no lo hizo. Dicho de otro modo, lo que extingue la contrata no es la decisión de la autoridad de no renovarla, sino que el vencimiento del plazo ${ }^{46}$.

Indica el disidente que los empleados a contrata tendrían plena conciencia de que gozan de beneficios remuneratorios superiores a aquellos de los que gozan los funcionarios de planta y cuyas funciones pueden ser homologables. Precisamente por lo anterior y como contrapartida, los referidos empleos son transitorios, por regla general no puedan cumplir funciones de jefatura y no integren de manera permanente la dotación del servicio al que pertenecen. De esta forma, no sería posible sostener que los funcionarios a contrata tengan confianza legítima, puesto que en nuestro ordenamiento jurídico no existe tal principio y porque históricamente todos los funcionarios a contrata saben que sus contratos vencen por el cumplimiento del plazo, tal como ocurre con el Presidente de la República, los alcaldes, el Fiscal Nacional, los jueces, etc. Además, agrega el disidente que dicha doctrina, conllevaría a mejorar las condiciones de los funcionarios a contrata, sin mejorar la situación de los funcionarios titulares, lo que sería contrario a la igualdad ante la ley. Con todo, agrega que los funcionarios a contrata ingresan más fácilmente a la Administración, con mejores grados y remuneraciones más ele-

45 Véase sentencias Corte Suprema rol No Rol No 7.295-2019, 8396-2019, 26.194-2019, 14.9152020 y $76.532-2020$.

46 Disidencia de la sentencia Corte Suprema Rol N 76.532-2020. 
vadas. Solo les afecta el carecer de carrera funcionaria y, en lo que importa, de estabilidad en el empleo ${ }^{47}$.

El disidente realiza un pormenorizado análisis de las ventajas que conlleva aplicar el principio de la confianza legítima a los empleados a contrata, en desmedro de los funcionarios titulares, quienes, frente a la misma situación, se verían en desigualdad. Ahora bien, se acierta al señalar que a las contratas solo les afecta la estabilidad en el empleo -si dejamos fuera la aplicación de la confianza legítima- lo cual es de la mayor relevancia, puesto que precisamente por aquello es que surgió dicha institución, la que vino a poner relativo coto a la precariedad del empleo en las contratas. No se debe olvidar, que antes de la vigencia de la confianza legítima, lo habitual era que la autoridad administrativa a través de una simple comunicación informaba de la no renovación de una contrata por no ser necesarios sus servicios, sin hacer referencia a ningún antecedente que dé cuenta de las circunstancias de hecho que justifiquen su decisión, es decir, de manera infundada.

Con lo anterior, no se quiere concluir que con la confianza legítima estas situaciones se acabaron, pero sin duda se ha morigerado, instando la jurisprudencia administrativa y judicial a dar cumplimiento al deber de motivación que pesa sobre las decisiones de los órganos de la administración del Estado al momento de poner término a una contrata.

Con todo, la tesis relatada, era lo habitual hasta antes del dictamen No 85.700, de la Contraloría, por lo que, como ya se advirtió, dificultosamente este criterio retorne a nuestra jurisprudencia predominante.

\section{Conclusión}

De lo expuesto es posible concluir lo siguiente:

1. Las prevenciones y disidencias referentes a las desvinculaciones del personal a contrata han tenido un importante efecto sobre la jurisprudencia mayoritaria, estableciéndose una clara tendencia en la tercera sala, desde el año 2016, en que las prevenciones y disidencias, posteriormente, se transforman en la posición dominante, siendo uno de los mayores exponentes de la situación en análisis el ministro Sergio Muñoz.

2. Algunas de las actuales disidencias y prevenciones estudiadas, tienen el suficiente sustento para ser consideradas en un futuro, como una vía posible para crear jurisprudencia nueva, no obstante en algunas de ellas -como lo es la disidencia del abogado integrante Pierry en relación a los concursos públicos-, se hace necesario reformar aspectos importantes del empleo público para que en la práctica dicha tesis sea aplicable, como lo sería por ejemplo, la obligatoriedad de que el ingreso a la administración del Estado del personal a contrata se realice por concurso público.

47 Ibíd. 
3. Hay importantes disidencias de las cuales no se vislumbra futuro esplendoroso, pero que, sin embargo, tienen un importante sustento legal, lo que las hace interesantes para el voto de mayoría, puesto que en este caso, tal como señala Sergio Verdugo obliga a mejorar la calidad de las sentencias por dos variables: (a) la existencia de discusión previa entre jueces de un mismo tribunal y; (b) la eventual existencia de un voto particular que presione a la mayoría a fundamentar de manera más acabada la sentencia ${ }^{48}$.

4. Finalmente, es posible concluir, que la integración de la tercera sala de la Corte Suprema influye notablemente en la jurisprudencia, la que en periodos puede ser cambiante, tal como lo señala Alejandro Vergara al indicar que durante el 2019, la mayoría de los ministros y abogados integrantes de la Sala zigzaguean constantemente, mostrando sin embargo en algunos períodos cierta estabilidad en su votación; en algunos casos podemos ver que votan de acuerdo a una tendencia, luego, resuelven conforme a la tendencia contraria y por último, fallan nuevamente de acuerdo a la primera tendencia; esto, en sucesivas ocasiones durante el período estudiado ${ }^{49}$.

\section{Bibliografía citada}

Ferrada Bórquez, J. (2011). Los procesos administrativos en el Derecho chileno. Revista de derecho (Valparaíso) (36), 251-277.

Fletcher, W. A. (2009). Dissent. Golden Gate University Law Review, 39 (3), 291-300.

García de Enterría, E. (1983). La lucha contra las inmunidades del poder (3a Ed.). Editorial Civitas.

McInTYRe, J. (2016). In defence of judicial dissent. Adelaide Law Review, 37 (2), 431-460.

Sото KLoss, E. (2012). Derecho Administrativo, Temas Fundamentales (3a Ed.). Editorial LegalPublishing.

Verdugo, S. (2011). Aportes del modelo de disidencias judiciales al sistema político: pluralismo judicial y debate democrático. Revista de derecho (Coquimbo), 18 (2), 217-272.

Vergara Blanco, A. (2019). El derecho administrativo ante la jurisprudencia de la Corte Suprema: Líneas y vacilaciones. Revista de Derecho Administrativo Económico (28), 5-175.

Vergara Blanco, A. (2020). El derecho administrativo ante la jurisprudencia de la Corte Suprema, II: Líneas y vacilaciones durante 2019. Revista de Derecho Administrativo Económico (31), 251-299.

\section{Normativa Citada}

Constitución Política de la República [Const.]. 17 de septiembre de 2005 (Chile).

Ley $N^{\circ} 20.948$ de 2016. Otorga una bonificación adicional y otros beneficios de incentivo al retiro para los funcionarios y funcionarias de los servicios públicos que se indican y modifica el título II de la Ley $\mathrm{N}^{\circ}$ 19.882. 25 de agosto de 2016. D. O. N 41.550.

Decreto $N^{\circ} 29$ de 2004 [con fuerza de ley]. Fija texto refundido, coordinado y sistematizado de la Ley $\mathrm{N}^{\circ} 18.834$, sobre estatuto administrativo. 16 de junio de 2004. D. O. $\mathrm{N}^{\circ} 38.112$.

Ley $N^{\circ} 18.883$ de 1989. Aprueba estatuto administrativo para funcionarios municipales. 15 de diciembre de 1989. D. O. N³3.557.

\footnotetext{
48 Verdugo 2011, 259.

49 Vergara 2019, 262.
} 
Ley $N^{\circ} 19.880$ de 2003. Establece bases de los procedimientos administrativos que rigen los actos de los órganos de la Administración del Estado. 22 de mayo de 2003. D.O. $N^{\circ} 37.570$.

Decreto Ley $N^{\circ} 1$ de 2000 [con fuerza de ley]. Fija texto refundido, coordinado y sistematizado de la Ley $\mathrm{N}^{\circ} 18.575$, orgánica constitucional de bases generales de la Administración del Estado. 13 de diciembre de 2000. D.O. N³7.113.

\section{Jurisprudencia citada}

Contraloría General de la República Dictamen N²2.766; 24 marzo 2016.

Contraloría General de la República. Dictamen N 85.700; 28 noviembre 2016.

Corte Suprema. Tercera Sala. Rol No 78.937-2016; 6 marzo 2017.

Contraloría General de la República. Dictamen N²9.461; 10 agosto 2017.

Corte Suprema. Tercera Sala. Rol N 34.532-2017; 13 noviembre 2017.

Corte Suprema. Tercera Sala. Rol No 39.403-2017; 15 enero 2018.

Contraloría General de la República. Dictamen N 6.400; 2 marzo 2018.

Corte Suprema. Tercera Sala. Rol No 1.399-2018; 22 mayo 2018.

Corte Suprema. Tercera Sala. Rol No 2.210-2018; 22 mayo 2018.

Corte Suprema. Cuarta Sala. Rol № 42.636-2017; 12 junio 2018.

Corte Suprema. Tercera Sala. Rol No 16.510-2018; 9 agosto 2018.

Corte Suprema. Tercera Sala. Rol No 16.455-2018; 9 agosto 2018.

Corte Suprema. Tercera Sala. Rol No 16.854-2018; 23 agosto 2018.

Corte Suprema. Tercera Sala. Rol No 16.858-2018; 23 agosto 2018.

Corte Suprema. Tercera Sala. Rol No 16.779-2018; 27 septiembre 2018.

Corte Suprema. Tercera Sala. Rol No 16.866-2018; 1 octubre 2018.

Corte Suprema. Tercera Sala. Rol N 16.887-2018; 3 octubre 2018.

Corte Suprema. Cuarta Sala. Rol No 4.591- 2018; 18 octubre 2018.

Corte Suprema. Tercera Sala. Rol No 24.943-2018; 20 diciembre 2018.

Corte Suprema. Tercera Sala. Rol No 29.477-2018; 19 febrero 2019.

Corte Suprema. Tercera Sala. Rol No 7.295-2019; 15 mayo 2019.

Corte Suprema. Tercera Sala. Rol No 31.312-2018; 15 julio 2019.

Corte Suprema. Tercera Sala. Rol No 8.396-2019; 12 agosto 2019.

Corte Suprema. Tercera Sala. Rol N 15.478-2019; 12 diciembre 2019.

Corte Suprema. Cuarta Sala. Rol No 15.615-2019; 3 enero 2020.

Corte Suprema. Tercera Sala. Rol N²6.194-2019: 28 enero 2020.

Corte Suprema. Tercera Sala. Rol No 18.881-2020; 29 abril 2020.

Corte Suprema. Tercera Sala. Rol No 14.915-2020; 6 mayo 2020.

Corte Suprema. Tercera Sala. Rol No 38.888-2019; 6 mayo 2020.

Corte Suprema. Tercera Sala. Rol N²9.869-2019; 5 junio 2020.

Corte Suprema. Tercera Sala. Rol N 76.532-2020; 7 julio 2020.

Corte Suprema. Tercera Sala. Rol No 71.955-2020; 3 agosto 2020. 